\title{
Blends of ground tire rubber devulcanized by microwaves/ HDPE - Part B: influence of clay addition
}

\author{
Fabiula Danielli Bastos de Sousa ${ }^{1 *}$, Júlia Rocha Gouveia ${ }^{1}$, Pedro Mário Franco de Camargo Filho", \\ Suel Eric Vidotti', Carlos Henrique Scuracchio', Leice Gonçalves Amurin ${ }^{2}$ and Ticiane Sanches Valera² \\ ${ }^{1}$ Centro de Engenharia, Modelagem e Ciências Sociais Aplicadas - CECS, Universidade Federal do ABC/UFABC, \\ Santo André, SP, Brazil \\ ${ }^{2}$ Departamento de Engenharia Metalúrgica e de Materiais, Escola Politécnica, \\ Universidade de São Paulo - USP, São Paulo, SP, Brazil \\ *fabiuladesousa@gmail.com
}

\begin{abstract}
The main objective of this work is to study the influence of clay addition on dynamically revulcanized blends of Ground Tire Rubber (GTR)/High Density Polyethylene (HDPE). GTR was previously devulcanized in a system comprised of a conventional microwave oven adapted with a motorized stirring, with a fixed microwave power and at various exposure times. The influence of clay addition on the final properties of the blends was evaluated in terms of mechanical, viscoelastic, thermal and rheological properties, with morphology being also analyzed. The results depict that the clay can modify the rheological behavior of the GTR phase, in addition to the thermal and mechanical properties of some blends.
\end{abstract}

Keywords: clay, recycling, GTR, devulcanization, HDPE.

\section{Introduction}

The reuse, recycling and recovery of waste cross-linked rubber are of great scientific and technological interest. Rubber requires a long period to degrade naturally due to its cross-linked structure and the presence of stabilizers and other additives $^{[1,2]}$, what consequently reduce its processability ${ }^{[3,4]}$.

Many efforts have been made regarding the preparation and characterization of polymer blends containing GTR and various thermoplastics, as a recycling alternative ${ }^{[5,6]}$. The properties of these materials depend on the concentration of the recycled material, as well as the adhesion between the phases $^{[7,8]}$. On the other hand, the adhesion between GTR and the polymer matrix is usually very weak as consequence of the three-dimensional structure generated by cross-linkings, in the case of blends in which the GTR is just ground ${ }^{[9-11]}$.

Cañavate et al. ${ }^{[6]}$ report that the lack of adhesion between phases is a consequence of the large particle size of GTR, superficial characteristics and cross-linked structure, which hamper its adsorption by the thermoplastic matrix molecules. In the production of thermoplastic vulcanized blends (TPVs) containing recycled rubbers, the addition of a virgin rubber or the promotion of the rubber devulcanization (at least partial) are pre-requisites to obtain resultant good mechanical properties ${ }^{[12]}$. The poor adhesion between the phases and the large particle size of the rubber phase facilitate the propagation of cracks and lead to a pronounced decline of the mechanical properties of the blends ${ }^{[13]}$.

In order to improve the properties of blends containing recycled rubbers, some authors devulcanize the rubber phase $^{[3,9,14-18]}$, or add functional fillers ${ }^{[19-33]}$. Besides, it is well known that dynamic vulcanization notoriously increases the adhesion and interaction between the phases.

Devulcanization provides to the vulcanized rubber the ability to flow and to be remolded ${ }^{[34]}$. So, during the processing of the blend, it acts by increasing the break-up ability and contributes to the refinement of the morphology $y^{[35]}$.
In recent years, a new type of polymer material has emerged: polymeric blends reinforced with nanofillers as organically modified clays. This new type of high performance material combines the advantages of polymeric blends and nanocomposites, by using small concentrations of nanofillers. In many cases, the nanofillers act as compatibilizing agent, decreasing the interfacial tension and promoting greater particle breakage during processing, thus decreasing the coalescence of the particles and increasing the morphology refinement ${ }^{[36]}$.

In this work, the influence of clay addition in the blends GTR devulcanized by microwaves/HDPE is investigated. The results show that the presence of clay in the blends can influence mechanical, thermal and rheological properties of some blends.

\section{Experimental}

\subsection{Materials}

HDPE IA-59, a grade for injection molding, was kindly supplied by Braskem (MFI = 7.3 g/10 min). Ground waste truck tire (GTR) separated from non elastomeric components, rubber accelerator N-tert-butyl-2-benzothiazole sulfenamide (TBBS) and sulfur were kindly supplied by Pirelli Pneus Ltda. Organically modified montmorillonite Cloisite 20A was kindly supplied by Bentonit União Nordeste.

\subsection{Devulcanization of GTR and mixture with vulcanization additives}

GTR was devulcanized in a system comprised of a conventional microwave oven adapted with a motorized stirring system with speed control. The devulcanization process was done by using the maximum power of the oven, 
i.e. $820 \mathrm{~W}$. The time at which the material was exposed to microwaves varied from 1 to 5 minutes and also 2-2, 2-2-2, and $3-3$, where the numbers represent the exposure time to microwaves (minutes) and the hyphen corresponds to an interval of 10 minutes between consecutive treatments, under stirring with the oven switched off.

The devulcanized GTR was mixed with the vulcanization additives by using a laboratory two roll mill PRENMAR for approximately 6 minutes at room temperature. To promote the dynamic revulcanization during the processing with the thermoplastic, $1 \mathrm{phr}$ of accelerator TBBS and $1 \mathrm{phr}$ of sulfur were added.

\subsection{Preparation of the blends}

The blends were prepared in an internal mixer coupled to a torque Rheometer Polylab 900 at $160{ }^{\circ} \mathrm{C}$ and $80 \mathrm{rpm}$ for 15 minutes. The compositions and nomenclature used for the blends are described in the Table 1. All the blends have $5 \mathrm{wt} \%$ of clay Cloisite $20 \mathrm{~A}$ in relation to the HDPE phase.

\subsection{Characterization}

Thermal properties of the HDPE phase were analyzed by Differential Scanning Calorimetry (DSC) in a DP Union DSC Q200 under nitrogen atmosphere. The samples were heated from room temperature to $190{ }^{\circ} \mathrm{C}$ and were held at this temperature for $3 \mathrm{~min}$ to erase their thermal history and destroy the HDPE crystalline nuclei. They were then cooled to $-90^{\circ} \mathrm{C}$ and were subsequently heated to $200^{\circ} \mathrm{C}$. All the steps were performed at a rate of $10^{\circ} \mathrm{C} / \mathrm{min}$.

Mechanical properties of the blends were analyzed by tensile tests in an Instron Universal Testing Machine 3369 with a $10 \mathrm{kN}$ load cell at a crosshead speed of $50 \mathrm{~mm} / \mathrm{min}$. The samples were prepared in the shape of plates by compression molding at $160{ }^{\circ} \mathrm{C}$ in a hydraulic press, and then the blends were cut into dumbbell shaped tensile test according to ASTM D412, type IV.

Rheological properties of the blends were analyzed by small amplitude oscillatory rheometry in frequency sweep mode, by using a parallel plate rheometer Anton Paar CTD450 (diameter $25 \mathrm{~mm}$, gap $1.3 \mathrm{~mm}, 0.5 \%$ strain for the viscoelastic linear response at $170{ }^{\circ} \mathrm{C}$ under inert atmosphere).

Dynamic mechanical properties of the blends were analyzed by using a DMA Q800 TA Instruments. The analyses were performed in Single Cantilever mode, frequency of $1 \mathrm{~Hz}$, temperature ranging from -100 to $140^{\circ} \mathrm{C}$ and heating rate of $3{ }^{\circ} \mathrm{C} / \mathrm{min}$.

A Jeol JMS-6701F Scanning Electron Microscope was used to observe the morphology of the blends. Working distances of each sample are shown in the respective micrographs. The samples were firstly pressed in a hydraulic press, cut, fractured just after being immersed in liquid nitrogen and then coated with gold by using a sputter coater.

\section{Results and Discussion}

Due to the large number of results, the work was divided into two parts. The part A covers more specifically the influence of the devulcanization of GTR on the properties of the blends, whereas part B is related to the influence of clay on their properties. Some results of the blends without clay are replicated from part $\mathrm{A}^{[35]}$ in order to deepen the analysis of the results.

\subsection{Processing behavior of the blends}

The literature presents some works in which dynamic vulcanization is analyzed during processing into internal mixer ${ }^{[22,37-44]}$, as performed on this work. In this particular case, the influence of a clay addition in the dynamic revulcanization reaction is analyzed.

During the mixing, just after the addition of the matrix phase and as soon as the torque measured by the equipment was stabilized, GTR (containing or not vulcanization additives) was added into the mixer, what permitted the analysis of the dynamic revulcanization behavior of the blends, which is reported in the Table 2. HDPE and clay were mixed manually before the introduction into the mixer. The $\mathrm{M}_{\text {Final }}$ values represent the torque measured by the equipment at the end of the mixing process.

CRA (Cure Rate Average) values were calculated according to Equation ${ }^{[45]}$ :

$$
C R A=\frac{1}{t_{90}-t s_{1}}
$$

where $t_{90}$ is the optimum cure time and ts $s_{1}$ the scorch time. The value is proportional to the average slope of torque

Table 1. Nomenclatures and compositions of the blends produced in this work. In the blends nomenclature, "+20A" is used to represent the presence of the clay Cloisite 20A.

\begin{tabular}{|c|c|c|c|c|}
\hline Nomenclature & $\begin{array}{c}\text { GTR amount } \\
(w t \%)\end{array}$ & $\begin{array}{c}\text { HDPE amount } \\
(w t \%)\end{array}$ & $\begin{array}{c}\text { Devulcanization time } \\
\text { of GTR ( } \mathrm{min})\end{array}$ & $\begin{array}{c}\text { Presence of } \\
\text { vulcanization additives }\end{array}$ \\
\hline 80GTR0/20HDPE+20A & 80 & 20 & - & - \\
\hline $80 \mathrm{GTR} 0+\mathrm{ad} / 20 \mathrm{HDPE}+20 \mathrm{~A}$ & 80 & 20 & - & Yes \\
\hline 80GTR $1+\mathrm{ad} / 20 \mathrm{HDPE}+20 \mathrm{~A}$ & 80 & 20 & 1 & Yes \\
\hline $80 \mathrm{GTR} 2+\mathrm{ad} / 20 \mathrm{HDPE}+20 \mathrm{~A}$ & 80 & 20 & 2 & Yes \\
\hline 80GTR3+ad/20HDPE+20A & 80 & 20 & 3 & Yes \\
\hline 80GTR4+ad/20HDPE+20A & 80 & 20 & 4 & Yes \\
\hline $80 \mathrm{GTR} 5+\mathrm{ad} / 20 \mathrm{HDPE}+20 \mathrm{~A}$ & 80 & 20 & 5 & Yes \\
\hline 80GTR2-2+ad/20HDPE+20A & 80 & 20 & $2-2$ & Yes \\
\hline 80GTR2-2-2+ad/20HDPE+20A & 80 & 20 & $2-2-2$ & Yes \\
\hline 80GTR3-3+ad/20HDPE+20A & 80 & 20 & $3-3$ & Yes \\
\hline
\end{tabular}


Table 2. Dynamic revulcanization behavior of the blends containing clay. The results of the blends without clay are replicated from de Sousa et al. ${ }^{[35]}$.

\begin{tabular}{|c|c|c|c|c|}
\hline Blend & $t_{90}(\min )$ & $\mathrm{ts}_{1}(\mathrm{~min})$ & $\operatorname{CRA}\left(\min ^{-1}\right)$ & $M_{\text {Final }}(d N . m)$ \\
\hline 80GTR0/20HDPE+20A & & & & 108.00 \\
\hline 80GTR0+ad/20HDPE+20A & 1.03 & 0.52 & 1.96 & 105.00 \\
\hline 80GTR $1+\mathrm{ad} / 20 \mathrm{HDPE}+20 \mathrm{~A}$ & 0.78 & 0.45 & 3.03 & 109.00 \\
\hline 80GTR2+ad/20HDPE $+20 \mathrm{~A}$ & 1.00 & 0.50 & 2.00 & 110.00 \\
\hline 80GTR3+ad/20HDPE+20A & 0.75 & 0.45 & 3.33 & 97.70 \\
\hline 80GTR4+ad/20HDPE+20A & 0.95 & 0.45 & 2.00 & 95.70 \\
\hline 80GTR5+ad/20HDPE+20A & 1.11 & 0.65 & 2.17 & 73.80 \\
\hline 80GTR2-2+ad/20HDPE+20A & 0.95 & 0.71 & 4.17 & 102.00 \\
\hline 80GTR2-2-2+ad/20HDPE+20A & 0.80 & 0.52 & 3.57 & 97.00 \\
\hline 80GTR3-3+ad/20HDPE+20A & 1.10 & 0.85 & 4.00 & 53.40 \\
\hline 80GTR0/20HDPE & & & & 107.00 \\
\hline 80GTR0+ad/20HDPE & 1.17 & 0.75 & 2.38 & 108.00 \\
\hline 80GTR1+ad/20HDPE & 0.95 & 0.75 & 5.00 & 106.00 \\
\hline 80GTR2+ad/20HDPE & 0.65 & 0.48 & 5.88 & 111.00 \\
\hline 80GTR3+ad/20HDPE & 1.15 & 0.95 & 5.00 & 92.50 \\
\hline 80GTR4+ad/20HDPE & 1.13 & 0.72 & 2.44 & 93.90 \\
\hline 80GTR5+ad/20HDPE & 1.01 & 0.68 & 3.03 & 63.10 \\
\hline 80GTR2-2+ad/20HDPE & 0.80 & 0.45 & 2.86 & 103.00 \\
\hline 80GTR2-2-2+ad/20HDPE & 0.75 & 0.50 & 4.00 & 96.20 \\
\hline 80GTR3-3+ad/20HDPE & 1.05 & 0.68 & 2.70 & 54.30 \\
\hline
\end{tabular}

versus time curve or, in other words, it is proportional to the rubber revulcanization speed ${ }^{[35]}$.

In general, but with some exceptions, the presence of clay did not influence $t_{90}$, ts and CRA values, possibly due to the low amount of clay in the blends. No significant differences were observed between the values of the final viscosities of the blends whether or not containing clay.

In addition and as reported previously ${ }^{[35]}, \mathrm{t}_{90}$ and $\mathrm{ts}_{1}$ values of the blends were much smaller than the values of the neat rubber obtained by using a rheometer. CRA values were consequently higher in comparison to the neat rubber, showing that the dynamic revulcanization reaction occurred with higher rate. It is attributed possibly to high shear rates generated within the internal mixer during processing.

\subsection{Oscillatory rheometry}

The storage modulus $\left(G^{\prime}\right)$ and complex viscosity $\left(\eta^{*}\right)$ of the blends, in function of the frequency, are summarized in the Figure 1.

In order to facilitate the analysis of the results, $G$ 'values at the minimum and maximum frequencies of the blends are summarized in the Table 3.

According to the Figure 1, the complex viscosity decreased as the frequency increased, which clearly shows the pseudoplastic behavior of the blends, assuming the Cox Merz rule ${ }^{[46-51]}$. No significant differences were observed between the blends in relation to the exposure time of GTR to microwaves, and also whether or not ${ }^{[35]}$ containing clay. Dynamic revulcanization increased G' values at minimum frequency.

$G^{\prime}$ values could be influenced by cross-linking density ${ }^{[52]}$ and/or blend morphology ${ }^{[42,43]}$, being that the morphology refinement and compatibility between the phases tend to increase the G' values. According to SEM micrographs, no conclusion about the morphology refinement of the blends can be made, but the mechanical properties results depict the poor adhesion between the phases, being that a possible particle detachment from the matrix occurs when applied an external stress. So, G' values are expected result from morphology and cross-linking density in the present work.

The blends containing GTR exposed to microwaves for long periods of time presented flattening of the curve $\mathrm{G}$ ' towards the same blends without clay. According to the literature ${ }^{[47,51,53]}$, flattening of the curve $G^{\prime}$ is due to the three-dimensional network formation. In nanocomposites, this behavior is observed in systems with intercalated and/ or exfoliated structures, and this is known as pseudosolid behavior $^{[54]}$. So, the presence of clay in these blends somehow helped the formation of this network, and the clay lamellae probably presented intercalated and/or exfoliated structures.

\subsection{Dynamic mechanical properties}

The temperature dependence of $\tan \delta$ of the blends is shown in the Figure 2.

According to the Figure 2 and as depicted in our previous work $^{[35]}$, there are two transitions related to the phases of the blends: around $-30{ }^{\circ} \mathrm{C}$ refers to the glass transition $\left(\mathrm{T}_{\mathrm{g}}\right)$ of the GTR and the other refers to $\alpha$ transition of the HDPE phase $\left(\mathrm{T}_{\alpha}\right)$ around $100{ }^{\circ} \mathrm{C}$. The existence of two distinct transitions proves the immiscible character of the blends, and the presence of clay on the blends seems not to alter this character. It can also be observed that there is a trend towards the reduction of the area under the peak related to GTR transition, as well as the reduction of the height of the same peak, which is due to mobility restriction generated by the cross-linkings of this phase ${ }^{[48,55,56]}$. The presence of clay did not alter significantly this behavior.

$\mathrm{T}_{\mathrm{g}}$ values of the devulcanized rubber and rubber phases of the blends (containing or not clay) were obtained from 

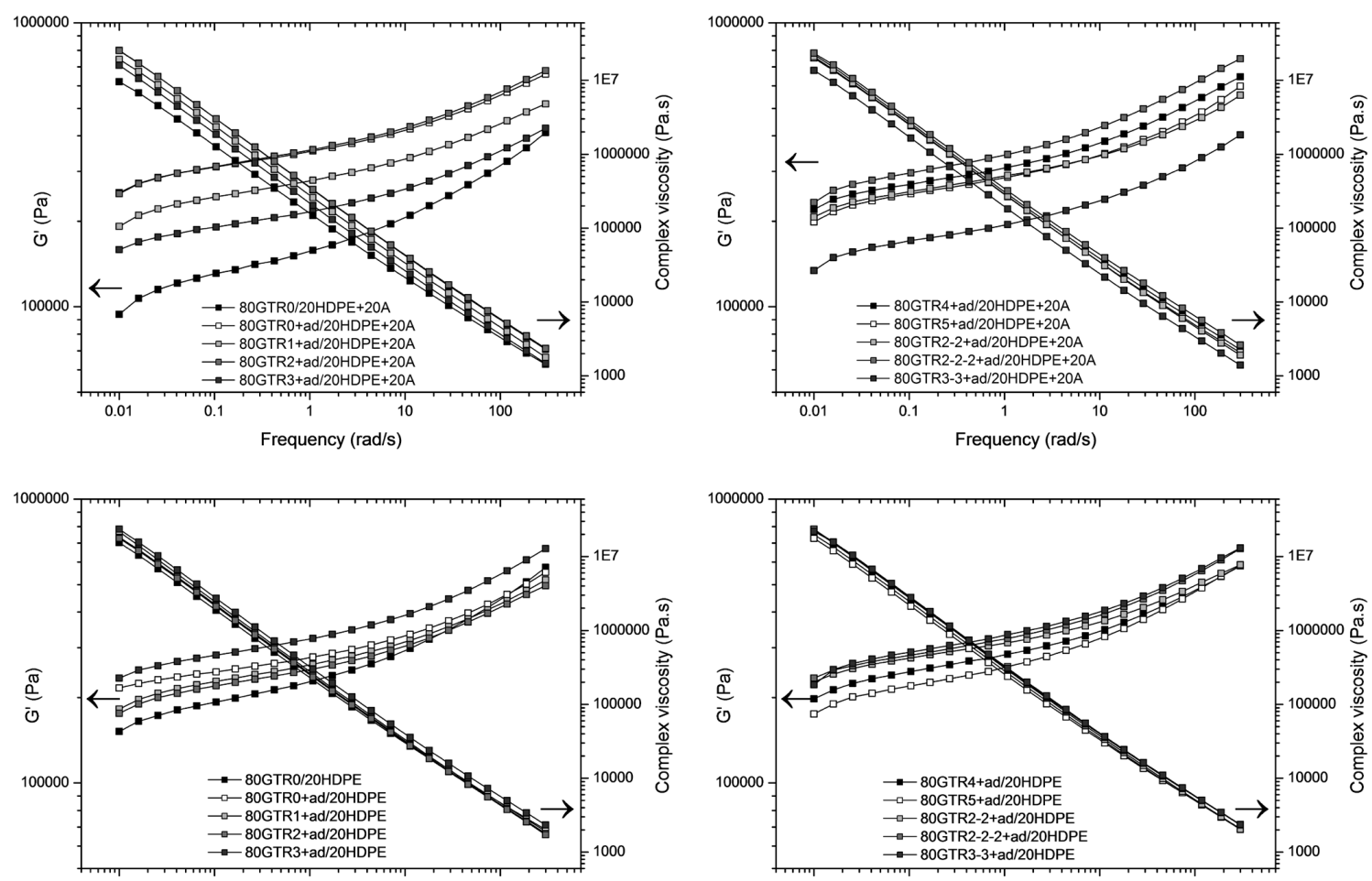

Figure 1. G' and $\eta^{*}$ versus frequency of the blends. The curves were separated for better visualization and analysis of results. The results of the blends without clay are replicated from de Sousa et al. ${ }^{[35]}$.

Table 3. G' $(\mathrm{Pa})$ at the minimum and maximum frequencies of the blends.

\begin{tabular}{lcc}
\hline \multicolumn{1}{c}{ Blend } & $\mathbf{G}^{\prime}(\mathbf{P a})$ at $\mathbf{0 . 0 1} \mathbf{~ r a d} / \mathbf{s}$ & $\mathbf{G}^{\prime}(\mathbf{P a})$ at $\mathbf{3 0 0} \mathbf{~ r a d} / \mathbf{s}$ \\
\hline 80GTR0/20HDPE+20A & $9.4 \times 10^{4}$ & $4.11 \times 10^{5}$ \\
80GTR0+ad/20HDPE+20A & $2.52 \times 10^{5}$ & $6.60 \times 10^{5}$ \\
80GTR1+ad/20HDPE+20A & $1.92 \times 10^{5}$ & $5.18 \times 10^{5}$ \\
80GTR2+ad/20HDPE+20A & $2.50 \times 10^{5}$ & $6.79 \times 10^{5}$ \\
80GTR3+ad/20HDPE+20A & $1.59 \times 10^{5}$ & $4.25 \times 10^{5}$ \\
80GTR4+ad/20HDPE+20A & $2.20 \times 10^{5}$ & $6.45 \times 10^{5}$ \\
80GTR5+ad/20HDPE+20A & $1.99 \times 10^{5}$ & $5.98 \times 10^{5}$ \\
80GTR2-2+ad/20HDPE+20A & $2.07 \times 10^{5}$ & $5.56 \times 10^{5}$ \\
80GTR2-2-2+ad/20HDPE+20A & $2.33 \times 10^{5}$ & $7.48 \times 10^{5}$ \\
80GTR3-3+ad/20HDPE+20A & $1.34 \times 10^{5}$ & $4.03 \times 10^{5}$ \\
\hline
\end{tabular}

the maximum peaks of the curves $\tan \delta$ versus temperature. These values are presented in the Figure 3.

According to the Figure 3, three zones of distinct $T_{g}$ behaviors can be determined. They were divided into continuous, dotted and dashed line zones, which are described below.

Continuous line zone: GTR was not exposed to microwaves. Even knowing that the clay was added first with the HDPE into the mixer, somehow it seems to act in the elastomer phase of blends containing GTR without being exposed to microwaves and without additives of vulcanization.

Dotted line zones: the final temperature of GTRs after the time of exposure to microwaves probably was not enough to provide high degree of devulcanization in the samples. Due to the low degree of devulcanization, there was not a significant change in $\mathrm{T}_{\mathrm{g}}$ of the rubber, which behaved just like a vulcanized one. The clay seems not have influenced the dynamic revulcanization reaction of rubber phase.

Dashed line zones: the final temperature of the GTRs after the time of exposure to microwaves was apparently enough to generate high degree of devulcanization in the sample. During processing of the blends, due to the devulcanization degree reached by the elastomeric phase of the samples, the rubber chains acquired some mobility, demonstrated by the increase in the $\mathrm{T}_{\mathrm{g}}$ values. In other words, the devulcanization level of the elastomeric phase influenced the dynamic revulcanization reaction, changing the $T_{g}$ value of this phase.

\subsection{Thermal properties by DSC}

The results of the DSC from the second heating cycle of the blends are summarized in the Table 4 . The crystallization degree was calculated according to Equation $2^{[57]}$ : 

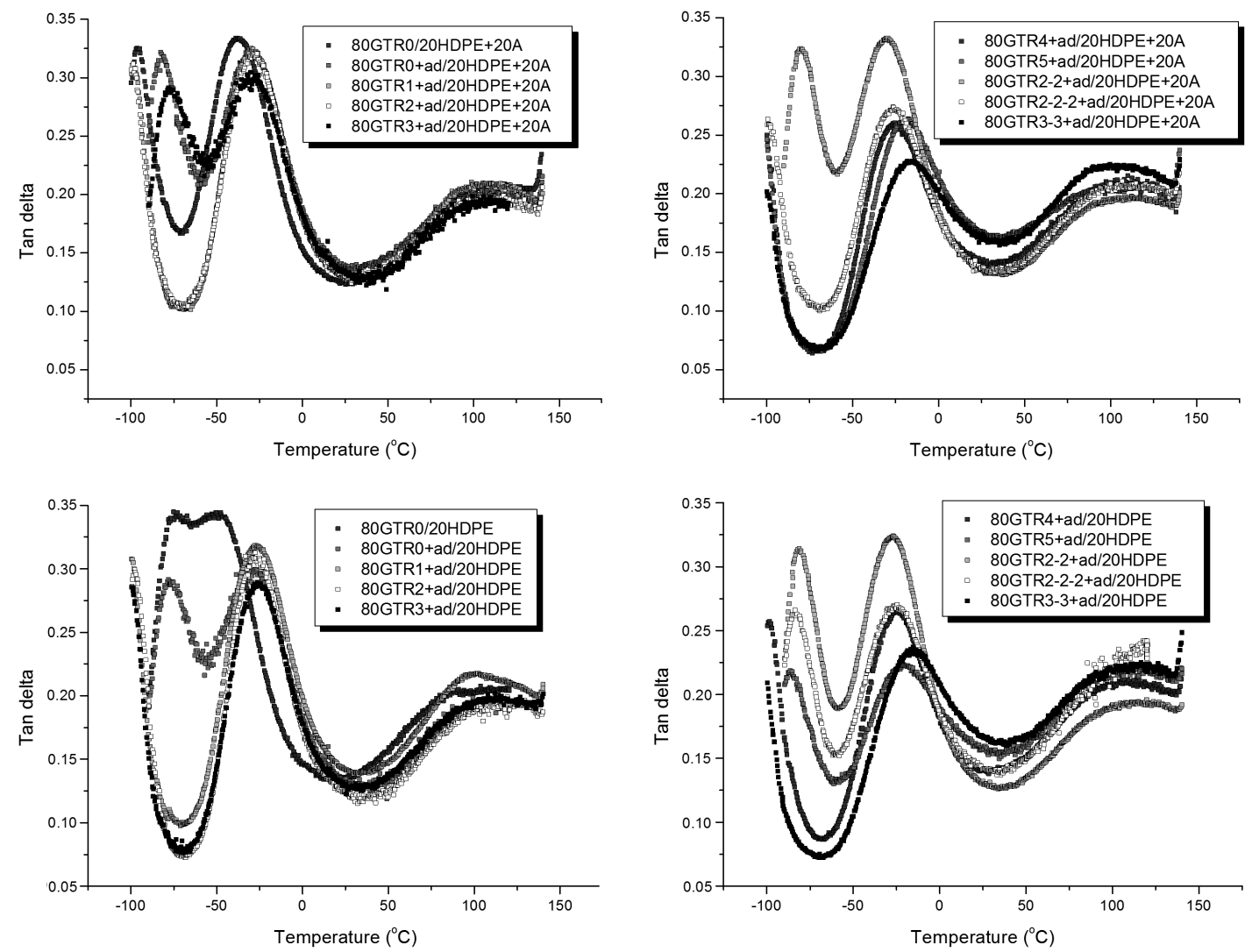

Figure 2. Tan $\delta$ versus temperature of the blends. The curves were separated for better visualization and analysis of results. The results of the blends without clay are replicated from de Sousa et al. ${ }^{[35]}$.

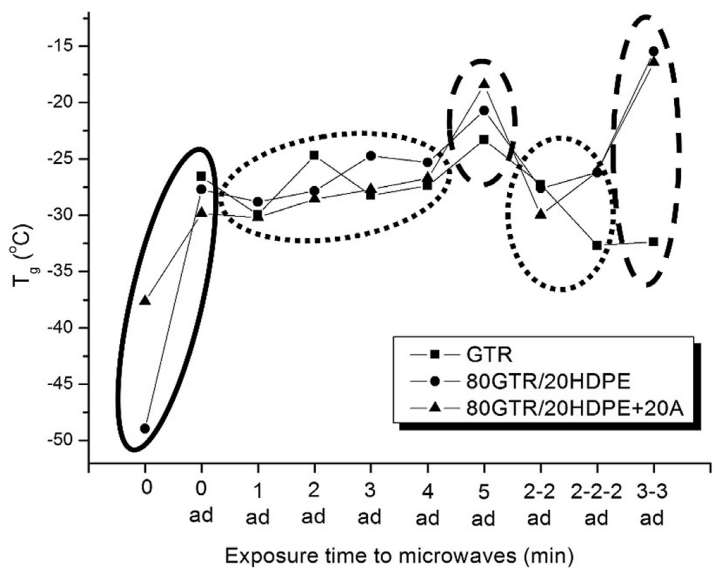

Figure 3. $\mathrm{T}_{\mathrm{g}}$ values of the devulcanized rubber and rubber phases of the blends as determined by DMA.

$$
\chi_{c}=\left[\Delta H_{m} /\left(\Delta H_{m 100} \cdot W_{H D P E}\right)\right] \cdot 100
$$

where $\chi_{c}$ is the crystallization degree, $\Delta H_{m}$ is the enthalpy of melting $(\mathrm{J} / \mathrm{g}), \Delta H_{m 100}$ is the enthalpy of melting of the HDPE $100 \%$ crystalline $(293 \mathrm{~J} / \mathrm{g})^{[58]}$ and $W_{H D P E}$ is the mass fraction of HDPE in blend.
According to previous work ${ }^{[35]}$, the crystallization degree of the HDPE phase was affected by the presence of the rubber, since the crystallization degrees of the HDPE phase were higher than the neat HDPE. It seems that the presence of clay did not influence significantly on the results. Only the blends 80GTR0 $+\mathrm{ad} / 20 \mathrm{HDPE}+20 \mathrm{~A}, 80 \mathrm{GTR} 2+\mathrm{ad} / 20 \mathrm{HDPE}+20 \mathrm{~A}$ and 80GTR4 $+\mathrm{ad} / 20 \mathrm{HDPE}+20 \mathrm{~A}$ presented higher crystallization degrees compared to the same blends without clay ${ }^{[35]}$. The increase of the crystallization degree of these blends probably influenced its mechanical properties, since the elongation at break of the blends $80 \mathrm{GTR} 0+\mathrm{ad} / 20 \mathrm{HDPE}+20 \mathrm{~A}$ and $80 \mathrm{GTR} 2+\mathrm{ad} / 20 \mathrm{HDPE}+20 \mathrm{~A}$ was lower than the same property of these blends without clay.

HDPE crystallinity was more sensitive to differences in the flow of GTR generated by its exposure to microwaves than by the clay addition, as consequence of changes in the number and average size of spherulites induced by the presence of rubber domains ${ }^{[59]}$.

\subsection{SEM}

SEM micrographs of some blends are presented in the Figure 4.

According to SEM micrographs and as also observed previously ${ }^{[35]}$, no conclusions can be made concerning the morphology refinement because it is not possible to distinguish between the phases from the presented SEM 
Table 4. Values of melting temperature, enthalpy of melting $\left(\Delta \mathrm{H}_{\mathrm{m}}\right)$ and crystallization degree $\left(\chi_{\mathrm{c}}\right)$ of the HDPE phase of the blends. The results of the blends without clay are replicated from de Sousa et al. ${ }^{[35]}$.

\begin{tabular}{|c|c|c|c|c|c|c|c|}
\hline Sample & $\mathrm{T}_{\mathrm{m}}\left({ }^{\circ} \mathrm{C}\right)$ & $\Delta \mathbf{H}_{\mathrm{m}}(\mathrm{J} / \mathrm{g})$ & $\chi_{c}(\%)$ & Sample & $\mathrm{T}_{\mathrm{m}}\left({ }^{\circ} \mathrm{C}\right)$ & $\Delta H_{\mathrm{m}}(\mathrm{J} / \mathrm{g})$ & $\chi_{\mathrm{C}}(\%)$ \\
\hline HDPE & 141.74 & 183.72 & 62.70 & & & & \\
\hline 80GTR0/20HDPE+20A & 135.34 & 48.96 & 83.55 & 80GTR0/20HDPE & 134.86 & 52.84 & 90.17 \\
\hline 80GTR0+ad/20HDPE+20A & 133.71 & 36.41 & 65.40 & 80GTR0+ad/20HDPE & 132.12 & 33.57 & 57.29 \\
\hline 80GTR1+ad/20HDPE+20A & 133.57 & 37.76 & 67.83 & 80GTR1+ad/20HDPE & 133.93 & 41.38 & 70.61 \\
\hline $80 \mathrm{GTR} 2+\mathrm{ad} / 20 \mathrm{HDPE}+20 \mathrm{~A}$ & 132.56 & 41.21 & 74.03 & 80GTR2+ad/20HDPE & 133.53 & 40.43 & 68.99 \\
\hline $80 \mathrm{GTR} 3+\mathrm{ad} / 20 \mathrm{HDPE}+20 \mathrm{~A}$ & 133.79 & 36.72 & 65.96 & 80GTR3+ad/20HDPE & 133.14 & 51.29 & 87.52 \\
\hline 80GTR4+ad/20HDPE $+20 \mathrm{~A}$ & 135.24 & 52.59 & 89.75 & 80GTR4+ad/20HDPE & 133.81 & 39.02 & 66.59 \\
\hline 80GTR5+ad/20HDPE+20A & 136.47 & 49.94 & 85.23 & 80GTR5+ad/20HDPE & 135.79 & 52.03 & 88.79 \\
\hline 80GTR2-2+ad/20HDPE+20A & 133.81 & 41.72 & 74.94 & 80GTR2-2+ad/20HDPE & 133.46 & 51.75 & 88.30 \\
\hline 80GTR2-2-2+ad/20HDPE+20A & 134.50 & 47.58 & 81.20 & 80GTR2-2-2+ad/20HDPE & 136.65 & 54.56 & 93.10 \\
\hline 80GTR3-3+ad/20HDPE+20A & 134.77 & 43.25 & 78.62 & 80GTR3-3+ad/20HDPE & 133.77 & 46.66 & 79.63 \\
\hline
\end{tabular}

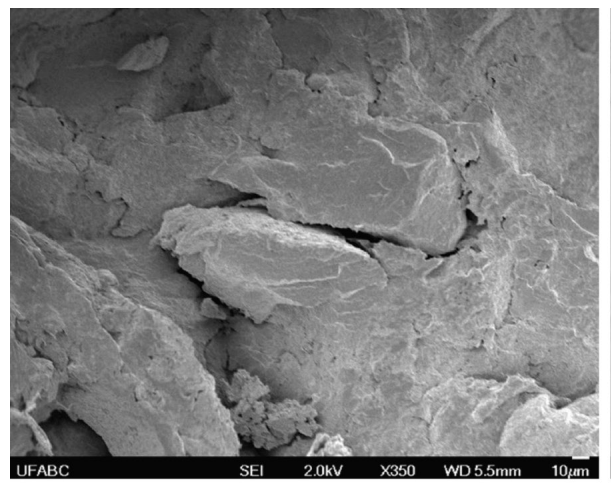

(a)

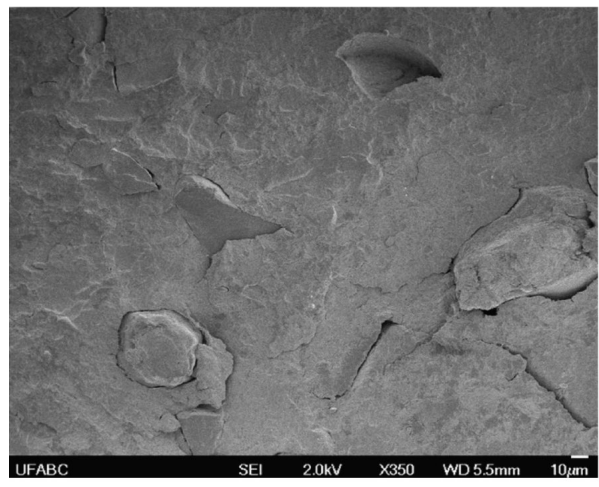

(c)

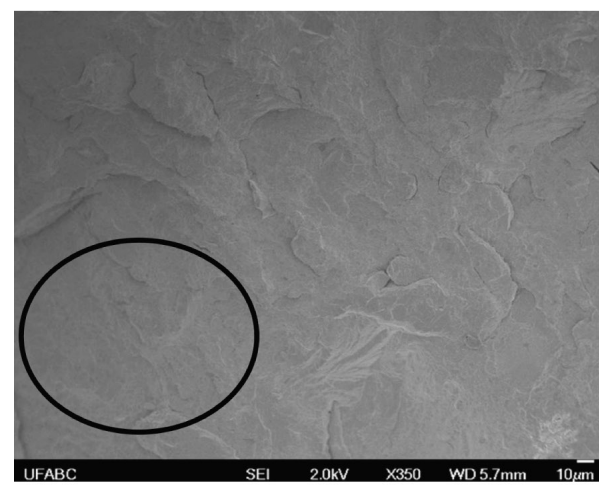

(e)

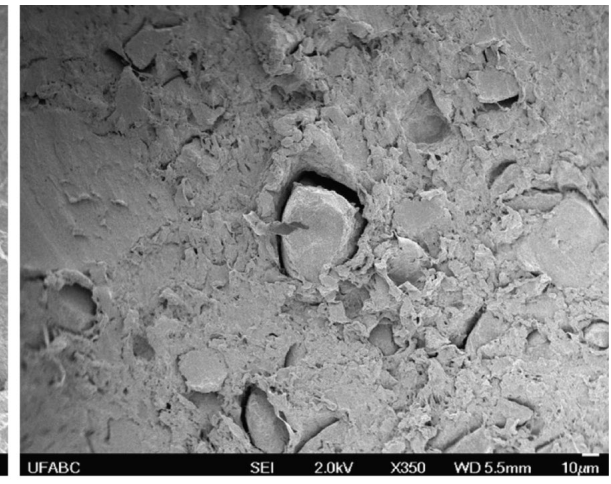

(b)

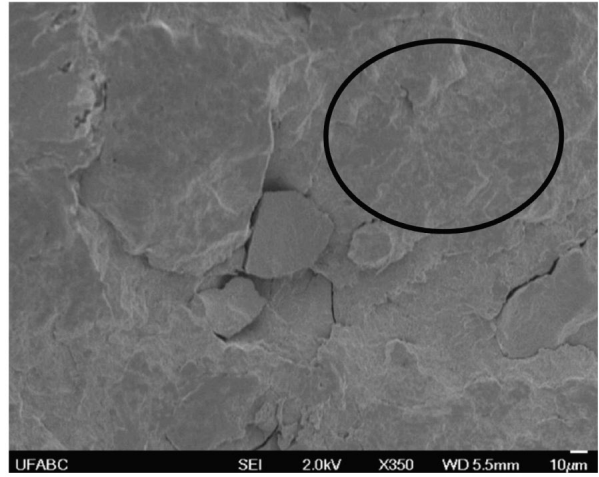

(d)

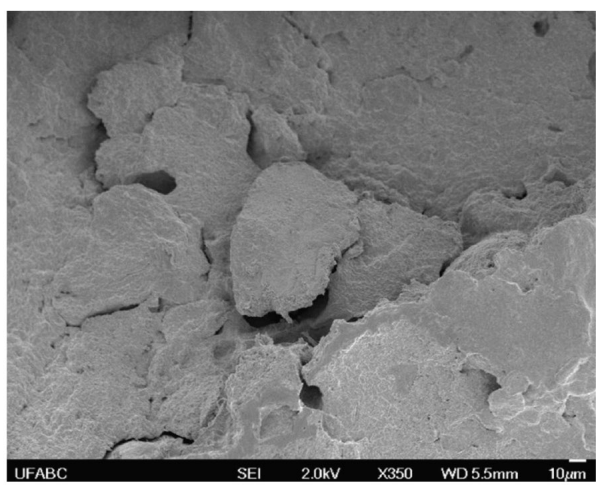

(f)

Figure 4. SEM micrographs of the blends: (a) 80GTR0/20HDPE+20A; (b) 80GTR0+ad/20HDPE+20A; (c) 80GTR3+ad/20HDPE+20A; (d) 80GTR4+ad/20HDPE+20A; (e) 80GTR2-2+ad/20HDPE+20A; (f) 80GTR3-3+ad/20HDPE+20A. 
micrographs. It could be observed that the blends containing GTR with longer exposure times to microwaves presented a less coarse surface in comparison to the other blends (detail: area inside the circle in the Figures $4 d$ and $4 \mathrm{e}$ ), result of a lower fracture resistance to the external force applied on the blends. This tendency was also observed in the results of mechanical properties of the blends (see section 3.6). It seems that the presence of clay somehow improved the interaction between the phases, as described by the discrete increase on the G' values of some blends containing clay. However no significant differences between the SEM micrographs could be observed.

\subsection{Mechanical properties}

The main results of the tensile tests of the blends whether or not containing clay are presented in the Figure 5.

The Young's modulus values increased with the increase of the exposure time of GTR to microwaves, with the exception of the blend 80GTR2+ad/20HDPE+20A. In the blends containing clay with GTR exposed to higher exposure times to microwaves, the Young's modulus values were higher than the blends without clay showing the reinforcement effect of the clays in the blends or, in other words, the stiffness increasing of the blends ${ }^{[60,61]}$. According to Braga et al. ${ }^{[54]}$, the increase on this value due to the addition of a clay in the blend could be attributed to the greatest degree of clay dispersion in the matrix, as also observed in the oscillatory rheometry results. Still about the Young's modulus of the blends containing clay, it could be observed that the blends showing the highest values were the ones with the highest crystallization degree values. Also according to Hills ${ }^{[62]}$, the vulcanization process increases the stiffness of the elastomeric chains due to the cross-linking formation, contributing to the increase of the Young's modulus value. These values follow the trend of $\mathrm{T}_{\mathrm{g}}$ value increasing as the exposure time of GTR to microwaves increased, so the increase of the cross-linking density could also be the responsible for the Young's modulus increasing.

Stress at break and tensile strength values decreased as the exposure time of GTR to microwaves got higher. Regarding the $\mathrm{T}_{\mathrm{g}}$ values of the elastomeric phase (section 3.3),

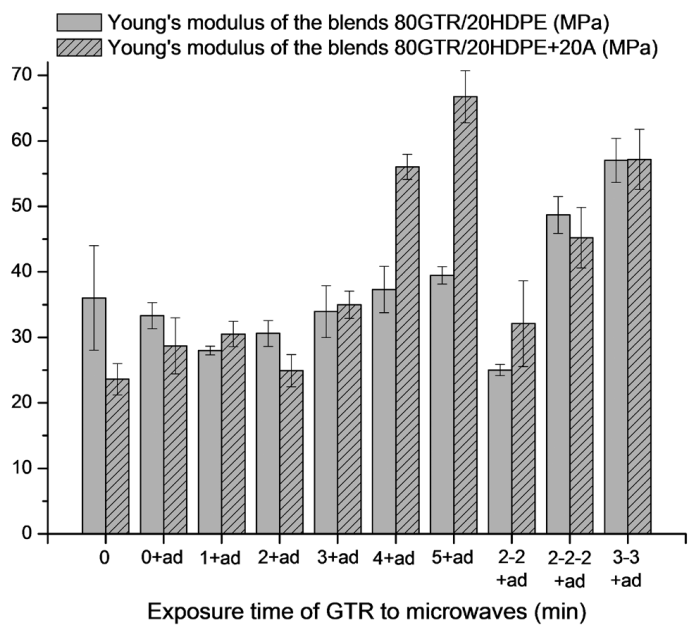

(a)

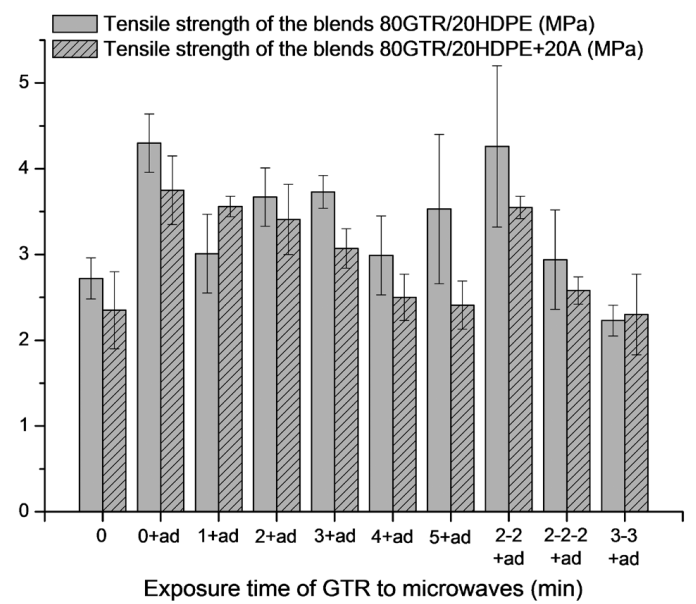

(c)

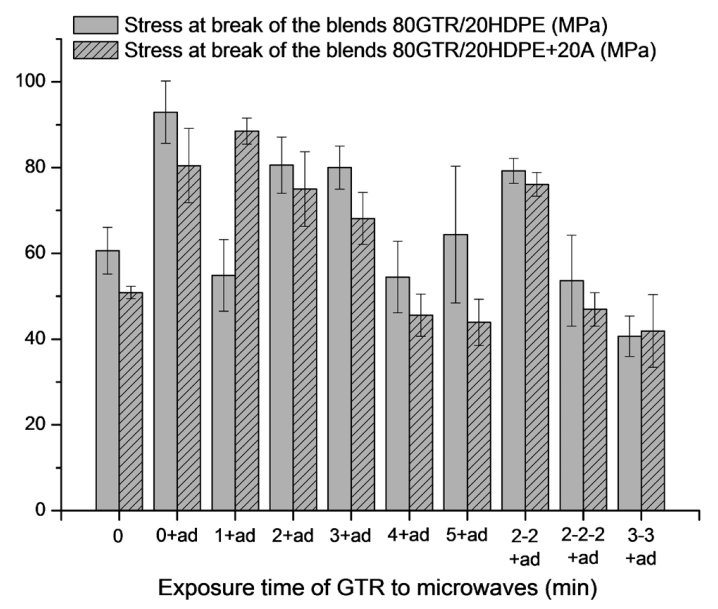

(b)

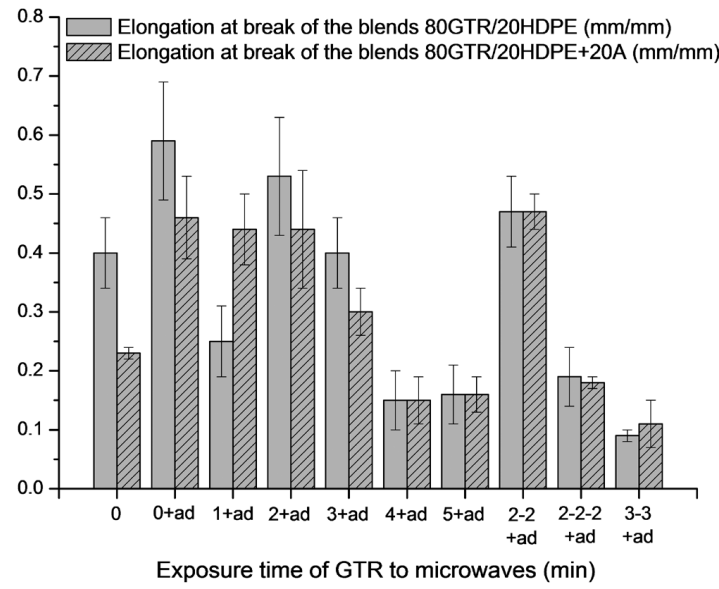

(d)

Figure 5. Young's modulus (a), stress at break (b), tensile strength (c), and elongation at break (d) in function of the exposure time to microwaves of the GTR, of the blends $80 \mathrm{GTR} / 20 \mathrm{HDPE}$ containing or not clay. 
it increased with the exposure time of GTR to microwaves. As the $\mathrm{T}_{\mathrm{g}}$ is related to the cross-linking density, this means that probably there was an increase of the cross-linking density. The tensile strength behavior is probably due to the reinforcement effect of clay. There was not a significant change in the elongation at break of the blends with the clay addition.

In general, the mechanical properties of the blends containing clay are not so good, especially the results of elongation at break, probably due to the poor adhesion between the phases ${ }^{[13,14,60,63]}$. According to the presented results, adhesion between the phases was not sufficient to promote good stress transference, resulting in the deterioration of the mechanical properties results.

As observed in the previous work ${ }^{[35]}$, one of the qualifying standards for a blend to be deemed as a TPV is to present typical elastomeric elongation, which has also not been verified in the results obtained, even after adding a nanometer filler like an organically modified clay. Thus, these blends are composed by $80 \%$ of a recycled material (GTR), what may have decreased its mechanical properties.

\section{Conclusions}

The properties of dynamically revulcanized blends containing HDPE and GTR devulcanized by microwaves were studied as function of clay addition, and different techniques were adopted.

According to the torque development during the mixing process, the presence of clay did not modify significantly the dynamic revulcanization reaction rate of the blends. The oscillatory rheometry results demonstrated that the lack of adhesion between the phases influenced the rheological properties of the blends, and some of them presented pseudosolid behavior. The dynamic mechanical properties depicted that there were differences in the $T_{g}$ values of the elastomeric phase, depending on the exposure time to microwaves. No conclusion about the morphology refinement of the blends could be made based on the SEM micrographs, but a less coarse surface of the blends containing GTR exposed to microwaves for longer periods was observed. According to mechanical properties results, the poor adhesion between the phases probably resulted in the deterioration of these properties. In contrast, clay seems to increase the stiffness of the blends containing GTR exposed to microwaves for longer periods due to the increase of the Young's modulus.

Summarizing, the presence of clay altered the rheological behavior, thermal and mechanical properties of some blends. The addition of clay may be a way to improve the properties of dynamically revulcanized blends containing recycled rubber as a whole.

\section{Acknowledgements}

The authors would like to thank Braskem, Pirelli and Bentonit União Nordeste for the material donation, FAPESP (process number 2010/15799-6) and CNPq (process number 201891/2011-5) for the financial support.

\section{References}

1. Wu, B., \& Zhou, M. H. (2009). Recycling of waste tyre rubber into oil absorbent. Waste Management (New York, N.Y.), 29(1), 355-359. http://dx.doi.org/10.1016/j.wasman.2008.03.002. PMid: 18455384.

2. Roche, N., Ichchou, M. N., Salvia, M., \& Chettah, A. J. (2011). Dynamic damping properties of thermoplastic elastomers based on EVA and recycled ground tire rubber. Journal of Elastomers and Plastics, 43(4), 317-340. http://dx.doi. org/10.1177/0095244311398631.

3. Zhang, X. X., Lu, C. H., \& Liang, M. (2011). Preparation of thermoplastic vulcanizates based on waste crosslinked polyethylene and ground tire rubber through dynamic vulcanization. Journal of Applied Polymer Science, 122(3), 2110-2120. http://dx.doi.org/10.1002/app.34293.

4. Magioli, M., Sirqueira, A. S., \& Soares, B. G. (2010). The effect of dynamic vulcanization on the mechanical, dynamic mechanical and fatigue properties of TPV based on polypropylene and ground tire rubber. Polymer Testing, 29(7), 840-848. http:// dx.doi.org/10.1016/j.polymertesting.2010.07.008.

5. Bianchi, O., Fiorio, R., Martins, J. N., Zattera, A. J., Scuracchio, C. H., \& Canto, L. B. (2009). Crosslinking kinetics of blends of ethylene vinyl acetate and ground tire rubber. Journal of Elastomers and Plastics, 41(2), 175-189. http://dx.doi. org $/ 10.1177 / 0095244308095015$.

6. Cañavate, J., Casas, P., Colom, X., \& Nogues, F. (2011). Formulations for thermoplastic vulcanizates based on high density polyethylene, ethylene-propylene-diene monomer, and ground tyre rubber. Journal of Composite Materials, 45(11), 1189-1200. http://dx.doi.org/10.1177/0021998310369596.

7. Anandhan, S., De, P. P., Bhowmick, A. K., De, S. K., \& Bandyopadhyay, S. (2003). Thermoplastic elastomeric blend of nitrile rubber and poly(styrene-co-acrylonitrile). II. Replacement of nitrile rubber by its vulcanizate powder. Journal of Applied Polymer Science, 90(9), 2348-2357. http://dx.doi.org/10.1002/ app.12862.

8. Anandhan, S., \& Bhowmick, A. K. (2013). Thermoplastic vulcanizates from post consumer computer plastics/nitrile rubber blends by dynamic vulcanization. Journal of Material Cycles and Waste Management, 15(3), 300-309. http://dx.doi. org/10.1007/s10163-012-0112-7.

9. Zhang, S. L., Zhang, Z. X., \& Kim, J. K. (2011). Study on thermoplastic elastomers (TPEs) of waste polypropylene/ waste ground rubber tire powder. Journal of Macromolecular Science, Part B: Physics, 50(4), 762-768. http://dx.doi. org/10.1080/00222341003785144.

10. Abadchi, M. R., Arani, A. J., \& Nazockdast, H. (2010). Partial replacement of NR by GTR in thermoplastic elastomer based on LLDPE/NR through using reactive blending: Its effects on morphology, rheological, and mechanical properties. Journal of Applied Polymer Science, 115(4), 2416-2422. http://dx.doi. org/10.1002/app.31356.

11. Punnarak, P., Tantayanon, S., \& Tangpasuthadol, V. (2006). Dynamic vulcanization of reclaimed tire rubber and high density polyethylene blends. Polymer Degradation \& Stability, 91(12), 3456-3462. http://dx.doi.org/10.1016/j. polymdegradstab.2006.01.012.

12. Kumar, C. R., Fuhrmann, I., \& Karger-Kocsis, J. (2002). LDPE-based thermoplastic elastomers containing ground tire rubber with and without dynamic curing. Polymer Degradation \& Stability, 76(1), 137-144. http://dx.doi.org/10.1016/S01413910(02)00007-1.

13. Rocha, M. C. G., Leyva, M. E., \& de Oliveira, M. G. (2014). Thermoplastic elastomers blends based on linear low density polyethylene, ethylene-1-octene copolymers and ground rubber 
tire. Polímeros: Ciência e Tecnologia, 24(1), 23-29. http:// dx.doi.org/10.4322/polimeros.2014.033.

14. Hong, C. K., \& Isayev, A. I. (2001). Plastic/rubber blends of ultrasonically devulcanized GRT with HDPE. Journal of Elastomers and Plastics, 33(1), 47-71. http://dx.doi. org/10.1106/5AMQ-XEAY-A05B-P1FY.

15. Luo, T., \& Isayev, A. I. (1998). Rubber/plastic blends based on devulcanized ground tire rubber. Journal of Elastomers and Plastics, 30(2), 133-160. http://dx.doi.org/10.1177/009524439803000204.

16. Kim, J. K., Lee, S. H., \& Hwang, S. H. (2003). Study on the thermoplastic vulcanizate using ultrasonically treated rubber powder. Journal of Applied Polymer Science, 90(9), 25032507. http://dx.doi.org/10.1002/app.12907.

17. Scaffaro, R., Dintcheva, N. T., Nocilla, M. A., \& La Mantia, F. P. (2005). Formulation, characterization and optimization of the processing condition of blends of recycled polyethylene and ground tyre rubber: mechanical and rheological analysis. Polymer Degradation \& Stability, 90(2), 281-287. http://dx.doi. org/10.1016/j.polymdegradstab.2005.03.022.

18. Hassan, M. M., Badway, N. A., Elnaggar, M. Y., \& Hegazy, E. A. (2014). Effects of peroxide and gamma radiation on properties of devulcanized rubber/polypropylene/ethylene propylene diene monomer formulation. Journal of Applied Polymer Science, 131(16), 1-10. http://dx.doi.org/10.1002/ app.40611.

19. Satapathy, S., Nag, A., \& Nando, G. B. (2010). Thermoplastic elastomers from waste polyethylene and reclaim rubber blends and their composites with fly ash. Process Safety and Environmental Protection, 88(2), 131-141. http://dx.doi. org/10.1016/j.psep.2009.12.001.

20. Naderi, G., Lafleur, P. G., \& Dubois, C. (2007). Microstructureproperties correlations in dynamically vulcanized nanocomposite thermoplastic elastomers based on PP/EPDM. Polymer Engineering and Science, 47(3), 207-217. http://dx.doi. org/10.1002/pen.20673.

21. Baghaei, B., Jafari, S. H., Khonakdar, H. A., Rezaeian, I., As'habi, L., \& Ahmadian, S. (2009). Interfacially compatibilized LDPE/POE blends reinforced with nanoclay: investigation of morphology, rheology and dynamic mechanical properties. Polymer Bulletin, 62(2), 255-270. http://dx.doi.org/10.1007/ s00289-008-0010-2.

22. Mani, S., Cassagnau, P., Bousmina, M., \& Chaumont, P. (2011). Morphology development in novel composition of thermoplastic vulcanizates based on PA12/PDMS reactive blends. Macromolecular Materials and Engineering, 296(10), 909-920. http://dx.doi.org/10.1002/mame.201000406.

23. Zhang, L. Y., Wan, C. Y., \& Zhang, Y. (2009). Investigation on morphology and mechanical properties of polyamide $6 /$ maleated ethylene-propylene-diene rubber/organoclay composites. Polymer Engineering and Science, 49(2), 209-216. http:// dx.doi.org/10.1002/pen.21201.

24. Feng, J. Y., Chan, C. M., \& Li, J. X. (2003). A method to control the dispersion of carbon black in an immiscible polymer blend. Polymer Engineering and Science, 43(5), 1058-1063. http:// dx.doi.org/10.1002/pen.10089.

25. Elias, L., Fenouillot, F., Majeste, J. C., \& Cassagnau, P. (2007). Morphology and rheology of immiscible polymer blends filled with silica nanoparticles. Polymer, 48(20), 6029-6040. http:// dx.doi.org/10.1016/j.polymer.2007.07.061.

26. Fang, Z. P., Xu, Y. Z., \& Tong, L. F. (2007). Effect of clay on the morphology of binary blends of polyamide 6 with high density polyethylene and HDPE-graft-acrylic acid. Polymer Engineering and Science, 47(5), 551-559. http://dx.doi. org/10.1002/pen.20675.

27. Fang, Z., Harrats, C., Moussaif, N., \& Groeninckx, G. (2007). Location of a nanoclay at the interface in an immiscible poly(e-caprolactone)/poly(ethylene oxide) blend and its effect on the compatibility of the components. Journal of Applied Polymer Science, 106(5), 3125-3135. http://dx.doi.org/10.1002/ app.26331.

28. Razmjooei, F., Naderi, G., \& Bakhshandeh, G. (2012). Preparation of dynamically vulcanized thermoplastic elastomer nanocomposites based on LLDPE/reclaimed rubber. Journal of Applied Polymer Science, 124(6), 4864-4873. http://dx.doi. org/10.1002/app.35558.

29. Zhang, Q., Yang, H., \& Fu, Q. (2004). Kinetics-controlled compatibilization of immiscible polypropylene/polystyrene blends using nano-SiO2 particles. Polymer, 45(6), 1913-1922. http://dx.doi.org/10.1016/j.polymer.2004.01.037.

30. Mishra, J. K., Ryou, J. H., Kim, G. H., Hwang, K. J., Kim, I., \& Ha, C. S. (2004). Preparation and properties of a new thermoplastic vulcanizate (TPV)/organoclay nanocomposite using maleic anhydride functionalized polypropylene as a compatibilizer. Materials Letters, 58(27-28), 3481-3485. http://dx.doi.org/10.1016/j.matlet.2004.07.003.

31. Tsai, Y., Wu, J. H., Wu, Y. T., Li, C. H., \& Leu, M. T. (2008). Reinforcement of dynamically vulcanized EPDM/PP elastomers using organoclay fillers. Science and Technology of Advanced Materials, 9(4), 1-7. http://dx.doi.org/10.1088/14686996/9/4/045005.

32. Wu, H. G., Ning, N. Y., Zhang, L. Q., Tian, H. C., Wu, Y. P., \& Tian, M. (2013). Effect of additives on the morphology evolution of EPDM/PP TPVs during dynamic vulcanization in a twin-screw extruder. Journal of Polymer Research, 20(10), 1-8. http://dx.doi.org/10.1007/s10965-013-0266-6.

33. Li, Y., Zhang, Y., \& Zhang, Y. X. (2004). Morphology and mechanical properties of HDPE/SRP/elastomer composites: effect of elastomer polarity. Polymer Testing, 23(1), 83-90. http://dx.doi.org/10.1016/S0142-9418(03)00065-5.

34. Scuracchio, C. H., Waki, D. A., \& Bretas, R. E. S. (2006). Caracterização térmica e reológica de borracha de pneu desvulcanizada por microondas. Polímeros: Ciência e Tecnologia, 16(1), 46-52. http://dx.doi.org/10.1590/S010414282006000100011.

35. de Sousa, F. D. B., Gouveia, J. R., Camargo, P. M. F., Fo., Vidotti, S. E., Scuracchio, C. H., Amurin, L. G., \& Valera, T. S. (2015). Blends of ground tire rubber devulcanized by microwaves/HDPE - Part A: influence of devulcanization process. Polímeros: Ciência e Tecnologia, 25(3), 256-264. http://dx.doi.org/10.1590/0104-1428.1747.

36. Taguet, A., Cassagnau, P., \& Lopez-Cuesta, J. M. (2014). Structuration, selective dispersion and compatibilizing effect of (nano)fillers in polymer blends. Progress in Polymer Science, 39(8), 1526-1563. http://dx.doi.org/10.1016/j. progpolymsci.2014.04.002.

37. Shahbikian, S., Carreau, P. J., Heuzey, M. C., Ellul, M. D., Cheng, J., Shirodkar, P., \& Nadella, H. P. (2012). Morphology development of EPDM/PP uncross-linked/dynamically crosslinked blends. Polymer Engineering and Science, 52(2), 309322. http://dx.doi.org/10.1002/pen.22084.

38. Antunes, C. F., Machado, A. V., \& van Duin, M. (2011). Morphology development and phase inversion during dynamic vulcanisation of EPDM/PP blends. European Polymer Journal, 47(7), 1447-1459. http://dx.doi.org/10.1016/j. eurpolymj.2011.04.005.

39. Antunes, C. F., van Duin, M., \& Machado, A. V. (2011). Morphology and phase inversion of EPDM/PP blends - Effect of viscosity and elasticity. Polymer Testing, 30(8), 907-915. http://dx.doi.org/10.1016/j.polymertesting.2011.08.013.

40. Antunes, C. F., van Duin, M., \& Machado, A. V. (2012). Effect of crosslinking on morphology and phase inversion of EPDM/ 
PP blends. Materials Chemistry and Physics, 133(1), 410-418 http://dx.doi.org/10.1016/j.matchemphys.2012.01.053.

41. Asaletha, R., Kumaran, M. G., \& Thomas, S. (1999). Thermoplastic elastomers from blends of polystyrene and natural rubber: morphology and mechanical properties. European Polymer Journal, 35(2), 253-271. http://dx.doi.org/10.1016/S00143057(98)00115-3.

42. Babu, R. R., Singha, N. K., \& Naskar, K. (2009). Dynamically vulcanized blends of polypropylene and ethylene octene copolymer: Influence of various coagents on mechanical and morphological characteristics. Journal of Applied Polymer Science, 113(5), 3207-3221. http://dx.doi.org/10.1002/app.30000.

43. Babu, R. R., Singha, N. K., \& Naskar, K. (2010). Interrelationships of morphology, thermal and mechanical properties in uncrosslinked and dynamically crosslinked $\mathrm{PP} / \mathrm{EOC}$ and $\mathrm{PP} /$ EPDM blends. Express Polymer Letters, 4(4), 197-209. http:// dx.doi.org/10.3144/expresspolymlett.2010.26.

44. Babu, R. R., Singha, N. K., \& Naskar, K. (2010). Effects of mixing sequence on peroxide cured polypropylene (PP)/ethylene octene copolymer (EOC) thermoplastic vulcanizates (TPVs). Part. I. Morphological, mechanical and thermal properties. Journal of Polymer Research, 17(5), 657-671. http://dx.doi. org/10.1007/s10965-009-9354-z.

45. de Sousa, F. D. B., \& Scuracchio, C. H. (2012). Vulcanization behavior of NBR with organically modified clay. Journal of Elastomers and Plastics, 44(3), 263-272. http://dx.doi. org/10.1177/0095244311424722.

46. Mirzadeh, A., Lafleur, P. G., Kamal, M. R., \& Dubois, C. (2012). The effects of nanoclay dispersion levels and processing parameters on the dynamic vulcanization of TPV nanocomposites based on PP/EPDM prepared by reactive extrusion. Polymer Engineering and Science, 52(5), 1099-1110. http://dx.doi. org/10.1002/pen.22178.

47. Babu, R. R., Singha, N. K., \& Naskar, K. (2011). Phase morphology and melt rheological behavior of uncrosslinked and dynamically crosslinked polyolefin blends: Role of macromolecular structure. Polymer Bulletin, 66(1), 95-118. http://dx.doi.org/10.1007/s00289-010-0328-4.

48. Cao, L. M., Cao, X. D., Jiang, X. J., Xu, C. H., \& Chen, Y. K. (2013). In situ reactive compatibilization and reinforcement of peroxide dynamically vulcanized polypropylene/ethylenepropylene-diene monomer tpv by zinc dimethacrylate. Polymer Composites, 34(8), 1357-1366. http://dx.doi.org/10.1002/ pc. 22550 .

49. Cui, L. M., Zhou, Z., Zhang, Y., Zhang, Y. X., Zhang, X. F., \& Zhou, W. (2007). Rheological behavior of polypropylene/ novolac blends. Journal of Applied Polymer Science, 106(2), 811-816. http://dx.doi.org/10.1002/app.26515.

50. Rajeshbabu, R., Gohs, U., Naskar, K., Thakur, V., Wagenknecht, U., \& Heinrich, G. (2011). Preparation of polypropylene (PP)/ ethylene octene copolymer (EOC) thermoplastic vulcanizates (TPVs) by high energy electron reactive processing. Radiation Physics and Chemistry, 80(12), 1398-1405. http://dx.doi. org/10.1016/j.radphyschem.2011.07.001.

51. Tang, Y. C., Lu, K., Cao, X. J., \& Li, Y. J. (2013). Nanostructured thermoplastic vulcanizates by selectively cross-linking a thermoplastic blend with similar chemical structures. Industrial \& Engineering Chemistry Research, 52(35), 12613-12621. http://dx.doi.org/10.1021/ie401853k.

52. Prut, E. V., Erina, N. A., Karger-Kocsis, J., \& Medintseva, T. I. (2008). Effects of blend composition and dynamic vulcanization on the morphology and dynamic viscoelastic properties of PP/ EPDM blends. Journal of Applied Polymer Science, 109(2), 1212-1220. http://dx.doi.org/10.1002/app.28158.
53. Babu, R. R., Singha, N. K., \& Naskar, K. (2010). Melt viscoelastic properties of peroxide cured polypropylene-ethylene octene copolymer thermoplastic vulcanizates. Polymer Engineering and Science, 50(3), 455-467. http://dx.doi.org/10.1002/pen.21553.

54. Braga, F. C. F., Oliveira, M. G., \& Furtado, C. R. G. (2012). Influence from the concentration of interfacial agent on the properties of PP/EPDM/organoclay nanocomposites. Polimeros: Ciência e Tecnologia, 22(3), 267-272. http://dx.doi.org/10.1590/ S0104-14282012005000033.

55. Babu, R. R., Singha, N. K., \& Naskar, K. (2011). Effects of mixing sequence on peroxide cured polypropylene (PP)/ ethylene octene copolymer (EOC) thermoplastic vulcanizates (TPVs). Part. II. Viscoelastic characteristics. Journal of Polymer Research, 18(1), 31-39. http://dx.doi.org/10.1007/ s10965-010-9388-2.

56. George, J., Varughese, K. T., \& Thomas, S. (2000). Dynamically vulcanised thermoplastic elastomer blends of polyethylene and nitrile rubber. Polymer, 41(4), 1507-1517. http://dx.doi. org/10.1016/S0032-3861(99)00302-X.

57. Machado, M. L. C., Pereira, N. C., de Miranda, L. E., Terence, M. C., \& Pradella, J. G. C. (2010). Study of mechanical and thermal properties of the polymer poly-3-hydroxybutyrate (PHB) and PHB/wood flour composites. Polimeros: Ciência e Tecnologia, 20(1), 65-71. http://dx.doi.org/10.1590/S010414282010005000011.

58. Huang, X. Y., Ke, Q. Q., Kim, C. N., Zhong, H. F., Wei, P., Wang, G. L., Liu, F., \& Jiang, P. K. (2007). Nonisothermal crystallization behavior and nucleation of LDPE/Al nano- and microcomposites. Polymer Engineering and Science, 47(7), 1052-1061. http://dx.doi.org/10.1002/pen.20784.

59. Domingues, N. S., Jr., Forte, M. M. D., \& Riegel, I. C. (2012). Thermal and rheological behavior of reactive blends from metallocene olefin elastomers and polypropylene. Polimeros: Ciência e Tecnologia, 22(3), 213-219. http://dx.doi.org/10.1590/ S0104-14282012005000030.

60. Kahar, A. W. M., Ismail, H., \& Othman, N. J. (2013). Properties of HVA-2 vulcanized high density polyethylene/ natural rubber/thermoplastic tapioca starch blends. Journal of Applied Polymer Science, 128(4), 2479-2488. http://dx.doi. org/10.1002/app.38471.

61. Passador, F. R., Pessan, L. A., \& Rodolfo, A. (2008). PVC/ NBR blends by reactive processing II: Physical-mechanical and morphological characterization. Polímeros: Ciência e Tecnologia, 18(2), 87-91. http://dx.doi.org/10.1590/S010414282008000200004

62. Hills, H. A. (1971). Heat transfer and vulcanisation of rubber. London: Applied Science Publishers.

63. Chen, J., Chen, J. W., Chen, H. M., Yang, J. H., Chen, C., \& Wang, Y. (2013). Effect of compatibilizer and clay on morphology and fracture resistance of immiscible high density polyethylene/polyamide 6 blend. Composites. Part B, Engineering, 54, 422-430. http://dx.doi.org/10.1016/j. compositesb.2013.06.014.

Received: Oct. 07, 2014

Revised: Mar: 05, 2015

Accepted: Apr. 22, 2015 